\title{
Filigrane
}

Écoutes psychothérapiques

\section{Le corps. Sur le divan. Dans le fauteuil II}

\section{Véronique Lussier et Sophie Gilbert}

Volume 18, numéro 2, automne 2009

Le corps. Sur le divan. Dans le fauteuil II

URI : https://id.erudit.org/iderudit/039284ar

DOI : https://doi.org/10.7202/039284ar

Aller au sommaire du numéro

Éditeur(s)

Revue Santé mentale au Québec

ISSN

1192-1412 (imprimé)

1911-4656 (numérique)

Découvrir la revue

Citer ce document

Lussier, V. \& Gilbert, S. (2009). Le corps. Sur le divan. Dans le fauteuil II.

Filigrane, 18(2), 3-4. https://doi.org/10.7202/039284ar d'utilisation que vous pouvez consulter en ligne.

https://apropos.erudit.org/fr/usagers/politique-dutilisation/ 


\title{
Le corps. Sur le divan. Dans le fauteuil II
}

\author{
véronique lussier et sophie gilbert
}

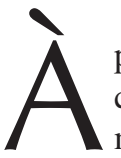

première vue, et en soupesant l'exemplaire qui se trouve entre vos mains, ce deuxième numéro du dossier sur le corps pourra paraître étonnamment mince. Svelte, certes, mais léger - que non. La réponse à l'appel d'articles lancé il y a deux ans a été, de fait, plutôt timide, mais les textes qui nous sont parvenus n'ont rien de chétif. Le corps est ici bien ancré, lourd de son poids de souffrance et d'inscription dans le réel, toujours aux frontières de la représentation et de l'à-venir. Rien d'éthéré dans les propos de ceux qui ont contribué à ce dossier! Et pourtant... peu de cliniciens se sont risqués à incarner ici leur pratique dans l'écriture. Comment comprendre ce silence relatif?

Qu'est-ce qui de ce «corps sur le divan/dans le fauteuil» se défile dès lors que l'on cherche à en témoigner ou à le figer en une trace écrite ? Le corps serait-il dérangeant parce que trop révélateur? Le «corporel» de la situation psychanalytique serait-il trop intime et ainsi, destiné à être préservé des regards indiscrets ? La corporéité serait-elle fondamentalement étrangère à la psychanalyse, ou est-ce qu'à l'inverse, le corps radicalement engagé dans le travail analytique s'avérerait trahi par toute parole — nécessairement réductrice — déposée hors la cure ? La question reste ouverte. Mais c'est avec d'autant plus de respect pour la rareté de ces témoignages que nous vous invitons à lire les contributions, originales et précieuses, de ce numéro.

Marie Desrosiers livre ici un fragment clinique illustrant le travail de passage qui permet «la fabrication d'une substance psychique utilisable pour l'analyse». Se situant dans une zone «intermédiaire entre la mise en acte corporelle, la construction d'images et la représentation de mots», elle rend compte d'un effet du symptôme d'une patiente sur ses propres constructions psychiques dans le cours de la cure. Avec une écriture abordant finement et résolument l'indescriptible, mise face au défi de «réanimer jusqu'à la matière inanimée », elle nous emmène au cœur d'un travail d'élaboration qui se mesure aux forces d'attraction, hors du champ de la représentation, d'un noyau traumatique entrevu.

Poursuivant le périple aux confins du dicible, Diane Aubin nous invite à faire une incursion dans l'univers souvent méconnu de l'intervention auprès des jeunes de la rue, en partageant le fruit d'une longue expérience clinique de la précarité et de l'addiction. La confrontation à la souffrance de ces jeunes exige la prise en 
Filigrane, automne 2009

compte du langage du corps, démarche inscrite «au cœur d'un apprivoisement mutuel », là où la psychothérapeute se trouvera conviée à «entrevoir l'innommable ou ressentir l'impensable». De ce travail qui «prend au corps», l'auteure nous livre les enjeux éthiques, thérapeutiques, et humanitaires, exigences vitales posées devant le mortifère. L'esquive n'est pas une option pour qui se refuse à faire l'impasse sur «les multiples avenues que le corps peut emprunter pour parler, se taire, interpeller ou fuir».

Dans un registre tout aussi vif, pourrait-on dire, Rose Dymetryszyn témoigne de sa rencontre troublante avec Kronos, un jeune homme dont la tourmente incisive atteint sans ambages le corps. Tatouages, cicatrices, sutures, meurtrissures, évoquent peut-être «l'écorce dure qui aide à se défendre de la fragmentation interne». Le «traumatique et la catastrophe psychique» ont laissé des traces sur un corps qui parle, qui «délivre son message en symptôme», et qui appelle la thérapeute en formation à un effort de métabolisation de ce chaos interne. À l'issue, tout à la fois prévisible et mystérieuse, de ce corps à corps psychothérapique, nul doute que Kronos aura imprimé sa marque dans la pensée de «l'apprenti-sorcier» et de ses lecteurs...

Et pour clore ce dossier sur le corps, quoi de mieux qu'un retour aux origines du palpable et du dire incarné? Florence Vinit nous initie aux fondements et aux pratiques de l'haptonomie, art et science du contact avec le bébé in utero, là où la main posée sur la paroi du ventre de la mère entame le dialogue avec l'enfant à venir. Phénoménologie du corps et de l'affectivité, reconnaissance du rôle des échanges tactiles dans la structuration psychique de l'individu: on ne saurait imaginer un rappel plus évocateur de l'inscription corporelle qui nous signe tout un chacun, depuis les premiers instants de la vie. 